\title{
BOAR SPERMATOZOA WITH MULTIPLE HEADS
}

\author{
YOSHIO KOJIMA \\ Laboratory of Reproductive Physiology, The Faculty of Agriculture, \\ Shizuoka University, 836 Ooya, Shizuoka, Post No. 420, Japan
}

(Received 4th Fune 1973)

This paper records findings on the semen of a Hampshire boar submitted for examination because of infertility. The boar was born in October 1969, and was mated by natural service in August 1970, to two Hampshire females both of which returned to service. Samples of semen were collected by artificial vagina on five occasions (Samples I to V) between 25th August 1970 and 26th January 1971. Two days after the first sampling (Sample I), the boar became ill. Clinical features included pyrexia (temperature $40 \cdot 8^{\circ} \mathrm{C}$ ) and inability to rise. Recovery occurred after symptomatic treatment with penicillin and 'toxicide'.

Following recovery, Samples II, III, IV and V were examined. The percentages of dead and morphologically abnormal spermatozoa were estimated from counts of 1000 spermatozoa on each of five slides from each ejaculate. Because of low sperm concentration, some smears were made from samples centrifuged for $10 \mathrm{~min}$ at $3000 \mathrm{rev} / \mathrm{min}$.

Counts of dead spermatozoa were made on smears stained with nigrosineosin (Swanson \& Bearden, 1951); counts of morphologically abnormal forms were made in smears stained by the method of Williams (1920).

Spermatozoa were arbitrarily classified as abnormal according to the morphological features of the head, mid-piece and main-piece. The frequencies recorded from counts of each class are summarized in Table 1. The recorded percentage of abnormal heads included those spermatozoa with multiple heads. No distinction was made between cytoplasmic heads at the neck and those situated more distally on the middle piece.

Measurements of $\mathrm{pH}$ were made with a Hitachi-Horiba $\mathrm{H}-5$ electric $\mathrm{pH}$ meter.

Motility was scored arbitrarily as,,,++++++ \pm and - according to the presence or absence of wave movement and the degree of progressive motility as seen by microscopical examination of undiluted semen.

The findings which are summarized in Table 1 show that the semen characteristics at the time of the first examination were within the normal range, but no examination of sperm morphology was made at this time.

Subsequent samples showed an abnormally low sperm concentration although ejaculate volume was normal and the percentage of live spermatozoa remained at a high level.

The frequencies of different morphological classes of spermatozoa varied between different samples but the most striking findings concerned the frequency of abnormal heads and, in particular, the occurrence of spermatozoa 
with multiple heads. Representaitive forms with two, three and four heads are shown in Pl. 1, Figs 2 to 6. The frequency of these was greatest in Sample II, as was the frequency of all abnormal heads. Most multiple-headed spermatozoa stained uniformly. The apparently single distal part of the flagellum was obviously thicker than normal and probably represented several fused flagella. Proximally, the composite flagellum sometimes opened out into separate flagella leading to the individual sperm heads. Some spermatozoa showed evidence of six or more heads but in these cases, the heads were grossly irregular in shape and staining affinity. Spermatozoa with multiple heads were invariably immotile.

The frequency of two-headed, three-headed and four-headed forms in Sample II was $3.8 \%, 0.36 \%$ and $0.04 \%$, respectively. Three-headed forms

Table 1. Characteristics of five semen samples from an infertile boar

\begin{tabular}{|c|c|c|c|c|c|}
\hline & \multicolumn{5}{|c|}{ Sample No. } \\
\hline & $I$ & $I I$ & $I I I$ & IV & $V$ \\
\hline Date of sampling & 26.8 .70 & 9.10 .70 & 2.11 .70 & 25.11 .70 & 26.1 .71 \\
\hline Ejaculate volume (ml) & 150 & 200 & 200 & 250 & 70 \\
\hline Sperm concentration $\left(\times 10^{8} / \mathrm{ml}\right)$ & $4 \cdot 5$ & $20 \cdot 1$ & 0.3 & $1 \cdot 3$ & $0 \cdot 1$ \\
\hline Motility* & +++ & 一 & \pm & ++ & - \\
\hline $\mathrm{pH}$ & $7 \cdot 15$ & $7 \cdot 4$ & $7 \cdot 2$ & $6 \cdot 8$ & $7 \cdot 0$ \\
\hline Dead spermatoza $(\%)$ & & $18 \cdot 6$ & $5 \cdot 9$ & $12 \cdot 4$ & $10 \cdot 6$ \\
\hline Spermatozoa with droplet $(\%)$ & & $37 \cdot 7$ & $52 \cdot 6$ & $92 \cdot 7$ & $87 \cdot 6$ \\
\hline $\begin{array}{l}\text { Abnormal forms }(\%) \\
\text { Head } \\
\text { Mid-piece } \\
\text { Main-piece }\end{array}$ & & $\begin{array}{r}13.26 \\
1.84\end{array}$ & $\begin{array}{r}11.41 \\
0.66\end{array}$ & $\begin{array}{l}3 \cdot 66 \\
0 \cdot 26\end{array}$ & $\begin{array}{l}0.68 \\
0.24\end{array}$ \\
\hline $\begin{array}{l}\text { Fractured } \\
\text { Coiled } \\
\text { Bent }\end{array}$ & & $\begin{array}{l}0.78 \\
5 \cdot 76 \\
1 \cdot 70\end{array}$ & $\begin{array}{l}0.34 \\
2 \cdot 82 \\
1 \cdot 28\end{array}$ & $\begin{array}{l}+ \\
3 \cdot 86 \\
1 \cdot 10\end{array}$ & $\begin{array}{r}0.11 \\
1.60 \\
15.55\end{array}$ \\
\hline
\end{tabular}

* For system of scoring, see text.

$(0.05 \%)$ were also observed in Sample III and two-headed forms $(2.76 \%)$ were also observed in this sample and again in Sample IV $(0.18 \%)$.

Although the evidence is inconclusive in the absence of information about sperm morphology before the boar's illness, it seems likely that the abnormal

\section{EXPLANATION OF PLATE 1}

Abnormal boar spermatozoa stained with Williams' or nigrosin-eosin stain at a magnification of $\times 1050$.

Fig. 1. Immature spermatozoa with cytoplasmic droplets (Williams' stain).

Fig. 2. Double-headed spermatozoon; note the size and shape of each head and the thickness of the flagellum (Williams' stain).

Fig. 3. Triple-headed spermatozoon; the twisting of the flagella gives the appearance of a single thread (Williams' stain).

Fig. 4. Triple-headed spermatozoon and an immature type (nigrosin-eosin stain).

FIG. 5. Tetra-headed spermatozoon showing laterally parallel arrangement of the heads (Williams' stain).

FIG. 6. Tetra-headed spermatozoon; note the different levels of the heads and the twisting of the flagella (Williams' stain). 
PLATE 1

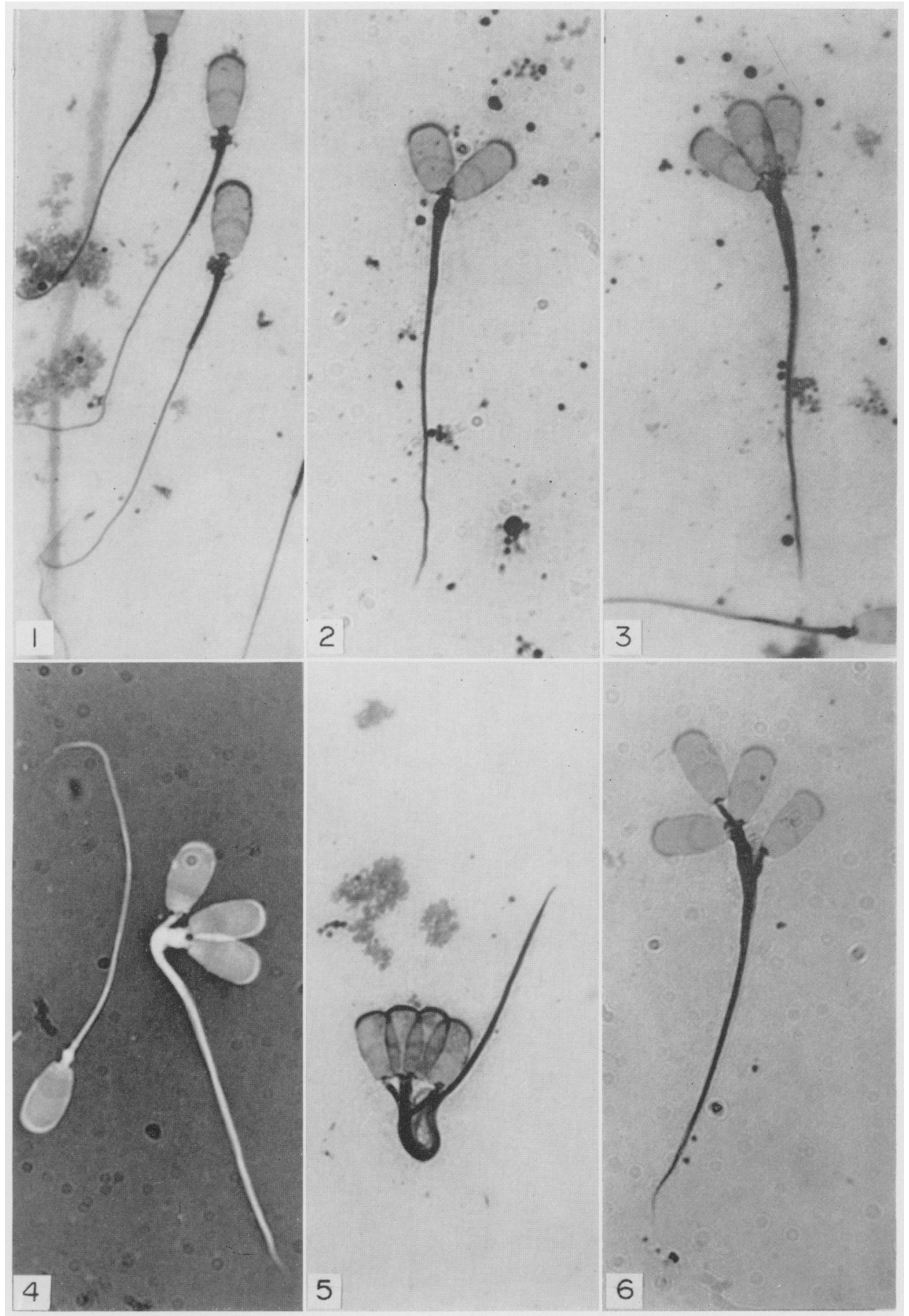

(Facing p. 538) 
features are the result of disturbances of spermatogenesis resulting from hyperthermia.

A tendency of epididymal spermatozoa to form aggregates has been observed in several mammalian species but this is unlikely to be the explanation of the findings recorded here. Double-headed spermatozoa have been frequently recorded in a variety of species and their significance has recently been discussed by Beatty \& Fechheimer (1972). The existence of cytoplasmic bridges between the developing germ cells of mammals (see Dym \& Fawcett, 1971) raises the possibility that failure of separation of members of a clone following a disturbance of spermatogenesis caused by febrile illness may explain the appearance of the multiple forms described here.

The author wishes to express his deep appreciation to Professor J. L. Hancock, The Royal Veterinary College, London, for reviewing the manuscript and offering valuable suggestions.

\section{REFERENCES}

BeAtTy, R. A. \& Fechueimer, N. S. (1972) Diploid spermatozoa in rabbit semen and their experimental separation from haploid spermatozoa. Biol. Reprod. 7, 267.

DYM, M. \& FAWCETT, D. W. (1971) Further observations on the numbers of spermatogonia, spermatocytes, and spermatids connected by intercellular bridges in the mammalian testis. Biol. Reprod. 4, 195.

Swanson, E. W. \& Bearden, H. J. (1951) An eosin-nigrosin stain for differentiating live and dead bovine spermatozoa. F. Anim. Sci. 10, 981.

Williams, W. W. (1920) Technique of collecting semen for laboratory examination with a review of several diseased bulls. Cornell Vet. 10, 87. Cited by Lagerlöf, N. (1936) Sterility in bulls. Vet. Rec. 48, 1159. 